\title{
Endoscopic Insufflation-Induced Gastric Barotrauma during Percutaneous Endoscopic Gastrostomy: A Report of Three Patients and Review of Literature
}

\author{
Avnish Kumar Seth ${ }^{1} \quad$ Rinkesh Kumar Bansal ${ }^{1}$ \\ ${ }^{1}$ Department of Gastroenterology and Hepatobiliary Sciences, \\ Fortis Memorial Research Institute, Gurugram, Haryana, India
}

J Digest Endosc 2021;12:103-106.

\author{
Address for correspondence AvnishKumar Seth, MBBS, MD(Med), \\ DM(Gastroenterology), Department of Gastroenterology and \\ Hepatobiliary Sciences, Fortis Memorial Research Institute, \\ Sector 44, Gurugram, Haryana 122002, India \\ (e-mail: akseth2003@yahoo.com).
}

\author{
Abstract \\ Keywords \\ - gastric barotrauma \\ - endoscopic \\ insufflation-induced \\ gastric barotrauma \\ - complications of \\ endoscopy \\ - complications \\ of percutaneous \\ endoscopic \\ gastrostomy
}

Background We report three patients with endoscopic insufflation-induced gastric barotrauma (EIGB) during upper gastrointestinal endoscopy (UGIE) for percutaneous endoscopic gastrostomy (PEG). A definition and classification of EIGB is proposed.

Materials and Methods Records of patients undergoing UGIE over 7 years (April 2013-March 2020) were reviewed. Patients who developed new onset of bleeding or petechial spots in proximal stomach, in an area previously documented to be normal during the same endoscopic procedure, were studied.

Results New onset of bleeding or petechial spots in proximal stomach occurred in $3 / 286(0.1 \%)$ patients undergoing PEG and in none of the 19,323 other UGIE procedures during the study period. All patients were men with median age 76 years (range 68-80 years), with no coagulopathy. Aspirin and apixaban were discontinued 1 week and 3 days prior to the procedure. Fresh blood was noted in the stomach at a median of 275 seconds (range 130-340) seconds after commencement of endoscopy. At retroflexion, multiple linear mucosal breaks of up to $3 \mathrm{~cm}$, with oozing of blood, were noted in the proximal stomach along the lesser curvature, close to the gastroesophageal junction in two patients. In the third patient, multiple petechial spots were noticed in the fundus. The plan for PEG was abandoned and the stomach deflated by endoscopic suction. There was no subsequent hematemesis, melena, or drop in hemoglobin. One week later, repeat UGIE in the first two patients revealed multiple healing linear ulcers of 1 to $3 \mathrm{~cm}$ in the lesser curvature and PEG was performed.

Conclusion Overinsufflation over a short duration during UGIE may lead to EIGB. Early detection is key and in the absence gastric perforation, patients can be managed conservatively.

\section{Introduction}

Inflation-induced gastric barotrauma (IGB) may occur when there is sudden gaseous distension of the stomach at high pressure. IGB has been reported following esophageal intubation during cardiopulmonary resuscitation (CPR), bag-mask

published online

June 23, 2020
Dol https://doi.org/ $10.1055 / \mathrm{s}-0041-1724134$ ISSN 0976-5042. ventilation, noninvasive positive pressure ventilation, use of oral sodium bicarbonate, and air swallowing during panic ascent in scuba diving..$^{-5}$ IGB usually manifests as transmural perforation of the proximal stomach, requiring surgical intervention. Reports of endoscopy-induced gastric barotrauma 
(EIGB) are rare. We report three patients who developed bleeding from proximal stomach following air insufflation during percutaneous endoscopic gastrostomy (PEG).

\section{Materials and Methods}

Records of patients undergoing upper gastrointestinal tract endoscopy (UGIE) at our institute from April 2013 to March 2020 were reviewed. All procedures were performed with Olympus GIF H-180 (Olympus Medical Systems Corp., Tokyo, Japan) endoscope and Olympus Processor EVIS Exera II CV-180 at "high" air setting. EIGB was defined as new onset of bleeding or petechial spots noted in proximal stomach, in an area previously documented to be normal, during the same endoscopic procedure. In patients who developed EIGB, the video recording was reviewed to note the interval between commencement of endoscopy and onset of bleeding. Procedure was abandoned and vital parameters, need for prolonged hospitalization, and blood transfusion were noted. All PEG procedures were performed as inpatients by the first author, with over 25 years of experience at endoscopy, using the "pull technique" under conscious sedation following preanesthesia assessment. Results of follow-up UGIE, where available, were scrutinized.

\section{Results}

Bleeding from ulcers or petechial spots in proximal stomach occurred in 3/286 (0.01\%) patients undergoing PEG, a procedure requiring prolonged air insufflation, and in none of 19,323 other UGIE procedures during the study period. All patients were male with a median age of 76 years (range 68-80 years). One patient was on aspirin, one on apixaban, and the third on both aspirin and apixaban (-Table 1). Aspirin and apixaban were discontinued 7 days and 3 days prior to PEG, respectively. Platelet count was 1.37 to $2.1 \times 10^{5} /$ $\mathrm{mm}^{3}$ and INR (international normalized ratio) 1.1 to 1.24 . There was no hiatus hernia and stomach lining was normal in all the three patients at the start of UGIE. Fresh blood or petechial spots were noted in the stomach at a median of 275 seconds (range 130-340 seconds) after commencement of endoscopy. At retroflexion, multiple linear mucosal breaks of up to $3 \mathrm{~cm}$ with oozing of blood were noted close to the gastroesophageal junction along the lesser curvature of stomach in two patients ( $\mathbf{- F i g}$. 1a,b). In the third patient (-Fig. 2), multiple petechial spots were noted in the fundus in the absence of a discernable mucosal break. None of the patients had retching, gagging, or cough during the procedure. The plan to go ahead with PEG was abandoned and the stomach deflated with endoscopic suction. There was no hemodynamic compromise and radiograph of abdomen did not reveal gas under the diaphragm. Patients were not fed anything for 24 hours and started on intravenous (IV) fluids and pantoprazole infusion at $8 \mathrm{mg}$ per hour. There was no subsequent hematemesis, melena, or drop in hemoglobin. All patients were discharged after 48 hours on oral pantoprazole $40 \mathrm{mg}$ twice daily. Repeat UGIE was performed after one week in the first two patients while the third did not consent for a repeat procedure. UGIE in the both patients revealed multiple healing linear ulcers of up to $3 \mathrm{~cm}$ (-Fig. 3) along the lesser curvature, close to the gastroesophageal junction. After counseling the family on risk of recurrence of IGB, PEG was performed in the same sitting, keeping a close watch on the proximal stomach. There was no complication or recurrence of bleeding from the ulcers in both patients.

\section{Discussion}

Sudden gaseous distension of the gastric cavity, secondary to high pressure, may lead to IGB, that usually manifests as transmural perforation of the proximal stomach, requiring surgical intervention. In a review of 67 patients with gastric perforation following CPR, aged 5 to 87 years, all perforations were located on the lesser curvature of the stomach, close to the gastroesophageal junction. ${ }^{6}$ The three most common risk factors identified were bystander-provided basic life support, use of bag mask, and esophageal intubation due to difficult airway. The patients manifested with pneumoperitoneum and the treatment was surgical. In a series of 705 autopsies performed after CPR by trained personnel, gastric dilatation was reported in $29.1 \%$ and gastric perforation in only $1(0.1 \%)$ subjects. $^{7}$

Endoscopic insufflation as a cause of gastric barotrauma is rare. Gastric perforation has been described in a 76-yearold lady following violent cough and gagging during UGIE, necessitating emergency laparatomy. ${ }^{8}$ Violent retching during endoscopy may result in tear in the proximal stomach and may be a contributory factor to EIGB. None of our three patients had retching, gagging, or coughing during the procedure. These factors are less likely to play a part when UGIE is performed under sedation, as was the case in most of our 19,323 patients. Endoscopic trauma as a cause is also unlikely because of the proximal location that could be visualized only with retroflexion. A $2-\mathrm{cm}$ perforation in the proximal

Table 1 Demography and clinical details of patients with endoscopic insufflation-induced gastric barotrauma (EIGB)

\begin{tabular}{|l|l|l|l|l|l|l|l|l|}
\hline Patient & Age in years & Sex & Indication of PEG & $\begin{array}{l}\text { Platelet count } \\
\left(\times 10^{5} / \mathbf{m m}^{3}\right)\end{array}$ & INR & $\begin{array}{l}\text { Dose of } \\
\text { aspirin }\end{array}$ & $\begin{array}{l}\text { Dose of } \\
\text { apixaban }\end{array}$ & $\begin{array}{l}\text { Time to onset } \\
\text { of EIGB (in } \\
\text { seconds) }\end{array}$ \\
\hline 1 & 76 & Male & Motor neuron disease & 2.11 & 1.10 & $75 \mathrm{mg}$ & Nil & 275 \\
\hline 2 & 68 & Male & $\begin{array}{l}\text { Cerebrovascular } \\
\text { accident }\end{array}$ & 1.37 & 1.15 & $75 \mathrm{mg}$ & $2.5 \mathrm{mg} \mathrm{BD}$ & 340 \\
\hline 3 & 80 & Male & Parkinson's disease & 1.85 & 1.24 & $\mathrm{Nil}$ & $5 \mathrm{mg} \mathrm{BD}$ & 130 \\
\hline
\end{tabular}

Abbreviations: BD, bi-daily; INR, international normalized ratio. 


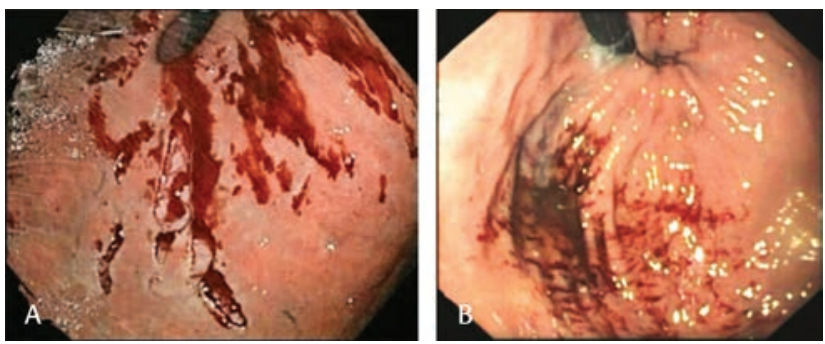

Fig. $1(\mathbf{a}, \mathbf{b})$ Endoscopic insufflation-induced gastric barotrauma grade 2 presenting as multiple linear mucosal breaks with active ooze at the lesser curvature, close to gastroesophageal junction.

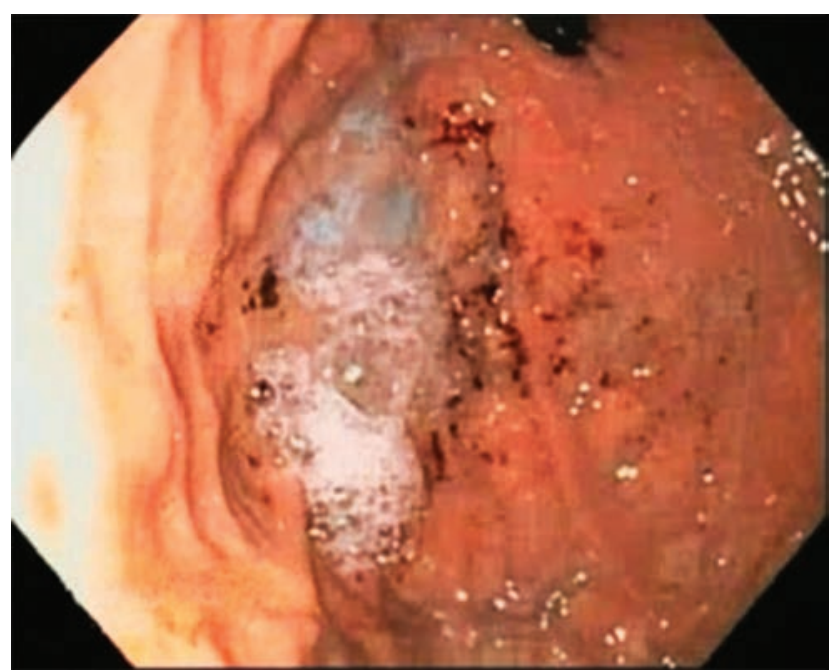

Fig. 2 Endoscopic insufflation-induced gastric barotrauma grade 1 presenting as appearance of petechial spots in the fundus with no discernable mucosal breaks.

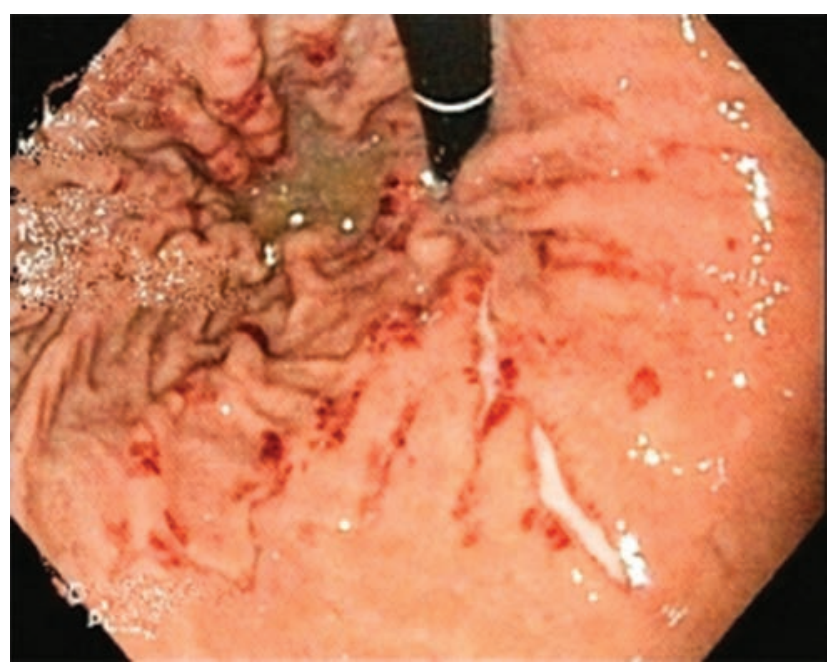

Fig. 3 Linear ulcers in proximal lesser curvature and hyperemic spots on all walls of proximal corpus and fundus, a week later, in the same patient as Fig. 1a. lesser curvature has been reported in a 73-year-old man following excessive gagging during PEG. ${ }^{9}$ In all these patients, the classic involvement of the proximal lesser curvature has been attributed to tethering of the gastroesophageal junction by gastrohepatic ligament and limited elasticity due to fewer gastric folds.

Mucosal breaks without perforation have been reported, though far less frequently. Lesions identical to the ones reported by us here have been described in a 67-year-old patient, the day after noninvasive positive-pressure ventilation, bag-mask ventilation, and endotracheal intubation. ${ }^{10}$

The fact that all three of our patients with IGB were seen in a setting of PEG points toward overinflation required for transillumination, a prerequisite for percutaneous gastric puncture, as one of the reasons for IGB. Large reviews on complications of PEG make no mention of EIGB. ${ }^{11}$ Surely, with insufflation one would expect excess air to escape from the stomach proximally or distally. An effective lower esophageal sphincter and a closed pylorus seem to be essential to produce EIGB. It is of interest that even though two of our patients had a lax lower esophageal sphincter (Hill grade II), none of the three patients had hiatus hernia, possibly preventing a proximal release of excess air. EIGB could, thus, include a wide spectrum ranging from petechial spots to perforation and we propose that EIBG should be defined as "new onset of petechial spots or bleeding from ulcers in proximal stomach with or without perforation, in an area previously documented to be normal during the same endoscopic procedure." A proposed classification of EIGB is shown in - Table 2. Use of carbon dioxide instead of room air during endoscopy may not affect EIGB as barotrauma develops within minutes. A meta-analysis on use of carbon dioxide for endoscopic procedures showed lower postprocedural pain and bowel distension in comparison to air insufflation during endoscopic procedures but there was no mention of reduced bleeding. ${ }^{12}$

Old age, male sex, and prior use of antiplatelet drugs and anticoagulants were common factors in all three of our patients. We went ahead with PEG in the presence of ulcers in two patients to avoid a third procedure. It may, however,

Table 2 Classification of endoscopic insufflation-induced gastric barotrauma

\begin{tabular}{|l|l|}
\hline Grade & Description \\
\hline 1 & Petechial lesions in proximal stomach without bleeding \\
\hline 2 & $\begin{array}{l}\text { Bleeding associated with ulceration in proximal } \\
\text { stomach }\end{array}$ \\
\hline 3 & $\begin{array}{l}\text { Bleeding associated with perforation in proximal } \\
\text { stomach }\end{array}$ \\
\hline
\end{tabular}


be prudent to allow ulcers to heal for four weeks before attempting PEG.

\section{Conclusions}

EIGB may occur following overinsufflation over a short duration during endoscopic procedures like PEG. Fresh onset of petechial spots or bleeding from mucosal breaks or transmural perforation in the proximal stomach may occur. Early recognition and prompt endoscopic decompression may prevent progression of mucosal tear to transmural perforation. Patients with bleeding from mucosal breaks without perforation may be managed conservatively.

\section{Conflict of Interest}

None declared.

\section{References}

1 Jalali SM, Emami-Razavi H, Mansouri A. Gastric perforation after cardiopulmonary resuscitation. Am J Emerg Med 2012;30(9):2091.e1-2091.e2

2 Malik SM, Rockacy M, Al-Khafaji A. Bleeding after bagging. Diagnosis: gastric rupture and massive pneumoperitoneum secondary to barotrauma from bag ventilation. Gastroenterology 2011;141(1):e16-e17
3 Nishimuea T, Shirai K, Nakao A, Kotani J. Gastric perforation because of non-invasive positive-pressure ventilation: review of complications. Surg Infections Case Reports 2016;1(1):41-43

4 Lemmon WT, Paschal GW. Rupture of the stomach following ingestion of sodium bicarbonate. Ann Surg 1941;114(6):997-1003

5 Titu LV, Laden G, Purdy GM, Wedgwood KR. Gastric barotrauma in a scuba diver: report of a case. Surg Today 2003;33(4):299-301

6 Spoormans I, Van Hoorenbeeck K, Balliu L, Jorens PG. Gastric perforation after cardiopulmonary resuscitation: review of the literature. Resuscitation 2010;81(3):272-280

7 Krischer JP, Fine EG, Davis JH, Nagel EL. Complications of cardiac resuscitation. Chest 1987;92(2):287-291

8 Wurm Johansson G, Nemeth A, Nielsen J, et al. Gastric rupture as a rare complication in diagnostic upper gastrointestinal endoscopy. Endoscopy 2013;45(Suppl 2 UCTN) :E391

9 Matsunaga Y, Goto A, Kaneko H, et al. Gastric rupture before puncture of the stomach in percutaneous gastrostomy. Endoscopy 2011;43(Suppl 2 UCTN) :E57

10 KüttnerMagalhães R, Marcos-Pinto R, Silva S, Pedroto I. Gastric barotrauma. Endoscopy 2014;46(Suppl 1 UCTN) :E564-E565

11 Rahnemai-Azar AA, Rahnemaiazar AA, Naghshizadian R, Kurtz A, Farkas DT. Percutaneous endoscopic gastrostomy: indications, technique, complications and management. World J Gastroenterol 2014;20(24):7739-7751

12 Wang WL, Wu ZH, Sun Q et al. Meta-analysis: the use of carbon dioxide insufflation vs. room air insufflation for gastrointestinal endoscopy. Aliment PharmacolTher 2012;35(10):1145-1154 